\title{
Why surgeons care about systemic chemotherapy for pancreatic cancer?
}

\author{
Stefan Heinrich \\ Department of General, Visceral and Transplantation Surgery, University Hospital of Mainz, Mainz, Germany \\ Correspondence to: Stefan Heinrich, MD. Department of General, Visceral and Transplantation Surgery, University Hospital of Mainz, 55131 Mainz, \\ Germany. Email: stefan.heinrich@unimedizin-mainz.de. \\ Comment on: Mavros MN, Moris D, Karanicolas PJ, et al. Clinical Trials of Systemic Chemotherapy for Resectable Pancreatic Cancer: A Review. \\ JAMA Surg 2021;156:663-72.
}

Submitted Sep 22, 2021. Accepted for publication Oct 18, 2021.

doi: $10.21037 /$ hbsn-21-398

View this article at: https://dx.doi.org/10.21037/hbsn-21-398

Pancreatic adenocarcinoma (PDAC) has become the seventh most frequent cause of cancer death in the world with increasing incidence independent of patient sex and age with smoking and alcohol consumption being the most important risk factors (1). The high mortality rate is mainly attributed to the biological characteristics of this disease: even small tumors reveal perineural invasion or local spread into lymph and blood vessels resulting in systemic disease. The estimated risk of occult distant metastasis at the time of surgery is $28 \%$ and $94 \%$ for tumors with a diameter of 1 and $3 \mathrm{~cm}$, respectively (2). Consequently, many patients present with disseminated or locally advanced disease and are at high risk for early tumor recurrence (3).

Due to the limited effect of chemotherapy, upfront surgery often included venous resections for presumed or proven vascular infiltration in the past, while arterial resections had been excluded for a long time due to its morbidity. Local treatment options such as surgery, tumor ablation and radiation therapy had been limited to a positively selected minority of patients with technically resectable, non-metastatic disease, in whom surgery was considered "potentially curative".

During the past two decades, adjuvant chemotherapy has proven to improve outcome after PDAC resection. Mavros et al. summarize the available evidence for chemotherapy in resectable PDAC (4). They confirm that adjuvant chemotherapy is the current standard of care, since FOLFIRINOX, nab-paclitaxel/gemcitabine and gemcitabine/capecitabine have proven superiority over gemcitabine-mono therapy. Also, the rationale of neoadjuvant therapy in upfront resectable PDAC is underlined in the manuscript: $>50 \%$ of patients do not get fit for adjuvant therapy in a reasonable time after surgery, and therefore neoadjuvant therapy may be beneficial (5).

The probability of an incomplete resection (R1/R2) as well as the recurrence rate can be predicted by imaging criteria, which classify tumors into locally unresectable (advanced), borderline resectable and upfront resectable tumors (Figure 1). A recent analysis of 268 patients demonstrated that the $\mathrm{R} 0$-resection rates in upfront resectable, borderline or unresectable disease were $81.6 \%$, $74.4 \%$ and $31.7 \%$, respectively, and the 5 -year survival rates were $32.2 \%, 19 \%$ and $0 \%$ (6). Also, the depth of invasion of the portal vein is predictive of the recurrence risk (7). These data confirm that upfront surgery should be avoided in borderline resectable and locally advanced PDAC.

The increasing success of modern poly-chemotherapy regimens (e.g., FOLFIRINOX, nab-paclitaxel, etc.) in the palliative and adjuvant setting, has also affected surgical treatment concepts of patients with (borderline) resectable, locally advanced as well as oligo-metastatic PDAC. Depending on the treatment aim, perioperative chemotherapy is defined as adjuvant, neo-adjuvant or palliative. While the definitions of adjuvant and palliative therapy are clear, preoperative therapies may be applied to achieve resectability in primarily unresectable disease, increase the R0-resection rate and decrease recurrence rates in borderline and primarily resectable tumors. In order to differentiate these situations, a differential definition of preoperative therapies into neoadjuvant (resectable), down- 
Resectable

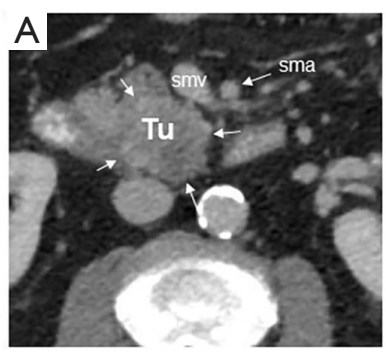

Borderline resectable

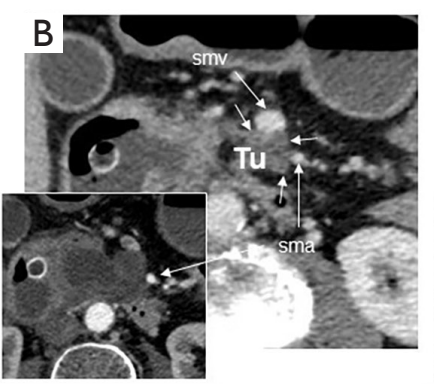

Locally advanced/unresectable

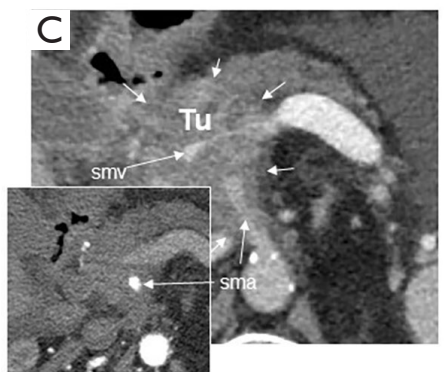

No reconstruction possible

\begin{tabular}{|c|c|c|c|c|}
\hline 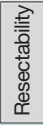 & $\begin{array}{l}\text { sma/celiac trunk } \\
\mathrm{PV} / \mathrm{smv}\end{array}$ & $\begin{array}{l}\text { No contact } \\
<180^{\circ} \text { contact }\end{array}$ & $\begin{array}{l}<180^{\circ} \text { contact } \\
>180^{\circ} \text { contact }\end{array}$ & $\begin{array}{l}>180^{\circ} \text { contact } \\
\text { No reconstruction possible }\end{array}$ \\
\hline 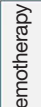 & Rationale & $\begin{array}{l}\text { Large proportion cannot } \\
\text { receive adjuvant chemo }\end{array}$ & Increased risk of local recurrence & $\begin{array}{c}\text { High risk of R1/R2-resection/ } \\
\text { unresectability }\end{array}$ \\
\hline 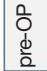 & Aim & Decrease recurrences & Increase R0-resection & Convert to resectable disease \\
\hline
\end{tabular}

Figure 1 Concept of borderline resectability (the definitions are a summary/interpretation from several international classifications): (A) shows a resectable tumor without contact to sma (superior mesenteric artery) or smv. (B) The CT reveals a tumor contact to the smv (160 ${ }^{\circ}$ ) and the sma (borderline resectable). (C) The CT scan shows a tumor which surronds the sma and occludes the smv confluence (locally advanced, unresectable). Short arrows: tumor. CT, computed tomography.

staging (oligo-metastatic) and down-sizing (borderline/ unresectable) has recently been proposed (8).

Various chemotherapy regimens are currently used to increase R0-resectability and improve long-term outcome of surgical patients with PDAC. The recent developments demonstrate the potential of systemic chemotherapy to convert primarily unresectable to resectable disease (down-sizing) (9). Particularly in this situation, imaging cannot reliably assess tumor response to chemotherapy. Therefore, extensive surgery including major venous and arterial resections are often required and can result in R0-resections. Also, neoadjuvant therapy increases the $\mathrm{R} 0$-resection rates in borderline and upfront resectable tumors (10). A pooled analysis of three randomized trials with upfront resectable PDAC reveals a longer diseasefree survival and lower morbidity in patients who received neoadjuvant therapy (3). Finally, patients with oligometastatic PDAC are increasingly offered surgery of the primary tumor and metastases in case of tumor response to the applied chemotherapy. The same concept is used for metachronous liver metastases, which may undergo ablation or surgery in multimodal concepts (11).

The majority of recurrences after an apparently curative resection is systemic. However, a substantial proportion of patients (20-25\%) develops isolated local recurrences $(12,13)$. A locally more extensive lymphadenectomy in the "triangle" between celiac and superior mesenteric arteries is supposed to decrease the risk of local recurrences (14). Furthermore, local treatment options may be preferred over systemic chemotherapy for such isolated local recurrences. Early detection of local recurrences is crucial to facilitate local treatments, and a recent analysis demonstrates that a structured follow-up improves the overall survival of PDAC patients (13).

The evidence is clear that the individual experience of the surgeon as well as the institutional case load are prognostic for patient outcome after pancreatic surgery. Although the morbidity of pancreatic surgery remains high, an operative mortality of $1.6 \%$ should be the benchmark for low-risk patients (15). Several scoring systems based on technical and laboratory parameters are able to predict the surgical risk of patients undergoing pancreatic surgery. An issue which gains increasing interest during recent years is, however, the health status of patients with PDAC at the time of presentation. The vast majority of PDAC (80\%) develop in the head of the pancreas causing obstructive jaundice, weight loss and impaired health status. Although the evidence contradicts the implantation of biliary stents 
in cholestatic patients whenever a timely resection is possible, patients with severe malnutrition may benefit from restoration of biliary flow and enteral nutrition over a defined preoperative period. This fact may be particulary important for elderly patients, which make up a major proportion of patients with PDAC, and who may benefit particularly from such prehabilitation protocols. In this light, a phase II-trial on neoadjuvant chemotherapy for resectable PDAC has shown, that two-month of biliary drainage and neoadjuvant chemotherapy significantly improved the nutritional status of affected patients and enabled safe surgery (16).

In summary, the success of modern chemotherapy regimen has dramatically improved the management and outcome of patients with PDAC and triggered new treatment concepts for patients with oligo-metastatic, locally advanced, borderline as well as upfront resectable PDAC. This success is mainly attributed to a more holistic understanding of the PDAC problem and multimodal treatment concepts. Further research will need to evaluate the indication and composition of neoadjuvant chemotherapy as well as other concepts such as preoperative prehabilitation for patients with PDAC.

\section{Acknowledgments}

Funding: None.

\section{Footnote}

Provenance and Peer Review: This article was commissioned by the editorial office, Hepatobiliary Surgery and Nutrition. The article did not undergo external peer review.

Conflicts of Interest: The author has completed the ICMJE uniform disclosure form (available at https://hbsn. amegroups.com/article/view/10.21037/hbsn-21-398/coif). The author has no conflicts of interest to declare.

Ethical Statement: The author is accountable for all aspects of the work in ensuring that questions related to the accuracy or integrity of any part of the work are appropriately investigated and resolved.

Open Access Statement: This is an Open Access article distributed in accordance with the Creative Commons Attribution-NonCommercial-NoDerivs 4.0 International License (CC BY-NC-ND 4.0), which permits the non- commercial replication and distribution of the article with the strict proviso that no changes or edits are made and the original work is properly cited (including links to both the formal publication through the relevant DOI and the license). See: https://creativecommons.org/licenses/by-nc-nd/4.0/.

\section{References}

1. Huang J, Lok V, Ngai CH, et al. Worldwide Burden of, Risk Factors for, and Trends in Pancreatic Cancer. Gastroenterology 2021;160:744-54.

2. Haeno H, Gonen M, Davis MB, et al. Computational modeling of pancreatic cancer reveals kinetics of metastasis suggesting optimum treatment strategies. Cell 2012;148:362-75.

3. Park W, Chawla A, O'Reilly EM. Pancreatic Cancer: A Review. JAMA 2021;326:851-62.

4. Mavros MN, Moris D, Karanicolas PJ, et al. Clinical Trials of Systemic Chemotherapy for Resectable Pancreatic Cancer: A Review. JAMA Surg 2021;156:663-72.

5. Altman AM, Wirth K, Marmor S, et al. Completion of Adjuvant Chemotherapy After Upfront Surgical Resection for Pancreatic Cancer Is Uncommon Yet Associated With Improved Survival. Ann Surg Oncol 2019;26:4108-16.

6. Park SJ, Jang S, Han JK, et al. Preoperative assessment of the resectability of pancreatic ductal adenocarcinoma on CT according to the NCCN Guidelines focusing on SMA/SMV branch invasion. Eur Radiol 2021;31:6889-97.

7. Fukuda S, Oussoultzoglou E, Bachellier P, et al. Significance of the depth of portal vein wall invasion after curative resection for pancreatic adenocarcinoma. Arch Surg 2007;142:172-9; discussion 180.

8. Heinrich S, Besselink M, Moehler M, et al. Opinions and use of neoadjuvant therapy for resectable, borderline resectable, and locally advanced pancreatic cancer: international survey and case-vignette study. BMC Cancer 2019;19:675.

9. Hackert T, Sachsenmaier M, Hinz U, et al. Locally Advanced Pancreatic Cancer: Neoadjuvant Therapy With Folfirinox Results in Resectability in $60 \%$ of the Patients. Ann Surg 2016;264:457-63.

10. Mokdad AA, Minter RM, Zhu H, et al. Neoadjuvant Therapy Followed by Resection Versus Upfront Resection for Resectable Pancreatic Cancer: A Propensity Score Matched Analysis. J Clin Oncol 2017;35:515-22.

11. Heinrich S, Lang H. Neoadjuvant Therapy of Pancreatic Cancer: Definitions and Benefits. Int J Mol Sci 2017;18:1622. 
12. Groot VP, Rezaee N, Wu W, et al. Patterns, Timing, and Predictors of Recurrence Following Pancreatectomy for Pancreatic Ductal Adenocarcinoma. Ann Surg 2018;267:936-45.

13. Daamen LA, Groot VP, Besselink MG, et al. Detection, Treatment, and Survival of Pancreatic Cancer Recurrence in the Netherlands: A Nationwide Analysis. Ann Surg 2020. [Epub ahead of print]. doi: 10.1097/ SLA.0000000000004093.

14. Schneider M, Strobel O, Hackert T, et al. Pancreatic

Cite this article as: Heinrich $\mathrm{S}$. Why surgeons care about systemic chemotherapy for pancreatic cancer? HepatoBiliary Surg Nutr 2021;10(6):860-863. doi: 10.21037/hbsn-21-398 resection for cancer-the Heidelberg technique. Langenbecks Arch Surg 2019;404:1017-22.

15. Sánchez-Velázquez P, Muller X, Malleo G, et al. Benchmarks in Pancreatic Surgery: A Novel Tool for Unbiased Outcome Comparisons. Ann Surg 2019;270:211-8.

16. Heinrich S, Pestalozzi BC, Schäfer M, et al. Prospective phase II trial of neoadjuvant chemotherapy with gemcitabine and cisplatin for resectable adenocarcinoma of the pancreatic head. J Clin Oncol 2008;26:2526-31. 